\title{
Scuttle flies (Diptera: Phoridae) reared from logs in Finland and N. W. Russia, including two new species
}

\author{
R. Henry L. Disney
}

Disney, R. H. L. 2009: Scuttle flies (Diptera: Phoridae) reared from logs in Finland and N. W. Russia, including two new species. — Entomol. Fennica 20: 257267.

Nine species of Megaselia Rondani have been reared from logs, in Finland and Northwest Russia. Megaselia excorticata sp. n. and M. tignorum sp. n. are described, the latter being a sibling species of M. setulipalpis Schmitz, which was also reared from logs.

Disney, R. H. L., Department of Zoology, University of Cambridge, Downing Street, Cambridge CB2 3EJ, U.K; E-mail: rhld2@hermes.cam.ac.uk

Received 20 November 2008, accepted 23 February 2009

\section{Introduction}

McLean (2000) has reviewed Palaearctic Diptera associated with dead wood. Detailed studies of their larval feeding habits are patchy, with some families often only listed at the family level. The scuttle flies (Diptera, Phoridae) are one such family. However, in Germany, Büchs (1983, 1988) studied the fauna obtained in emergence traps attached to the trunks and branches of living woodland trees and identified the Phoridae to the species level. Named species reared from dead wood are limited to a few reports only. These include Megaselia fungivora (Wood) reared from pupae found under the bark of beech, rowan and conifer logs in England (Disney 1979, 1994); M. obscuripennis (Wood) larvae inhabiting rotting wood, where they parasitise the larvae of Sciaridae (Disney, 1980); M. shawi Disney reared from a dead willow (Salix) trunk (Disney 2006); M. frameata Schmitz and $M$. robertsoni Disney reared from pupae found under the bark of a spruce stump (Picea) in Norway (Disney 2008) and Triphleba gracilis (Wood) reared from pupae found under the bark of fallen trees (Larix decidua and Picea abies) (Disney 1979). M. frameata has been reared from the sporophores of several species of fungi (e.g. Disney 1994).

During an investigation into the saproxylic insects carried out by the Friendship Park Research Centre (Kuhmo Regional Environment Centre) in Kuhmo, eastern Finland, numbers of Phoridae were obtained from logs placed in emergence sacks. Emerged flies were sorted and sent to the Malloch Society (Scotland) for further treatment and identification. The specimens of Phoridae were passed to me by David Robertson (National Museums of Scotland).

\section{Methods}

480 trees from 6 sites, in Finland and Northwest Russia, were felled in 2003. Parts of these trees were removed annually and these harvested logs were placed in rearing sacks. The logs were sampled from the base, mid and upper (canopy) trunk region, as well as branches separately $(\mathrm{G}$. Várkonyi personal communication). The emerging insects were collected, preserved in alcohol and subsequently mounted on slides in Berlese Fluid (Disney 2001). A holotype from the 

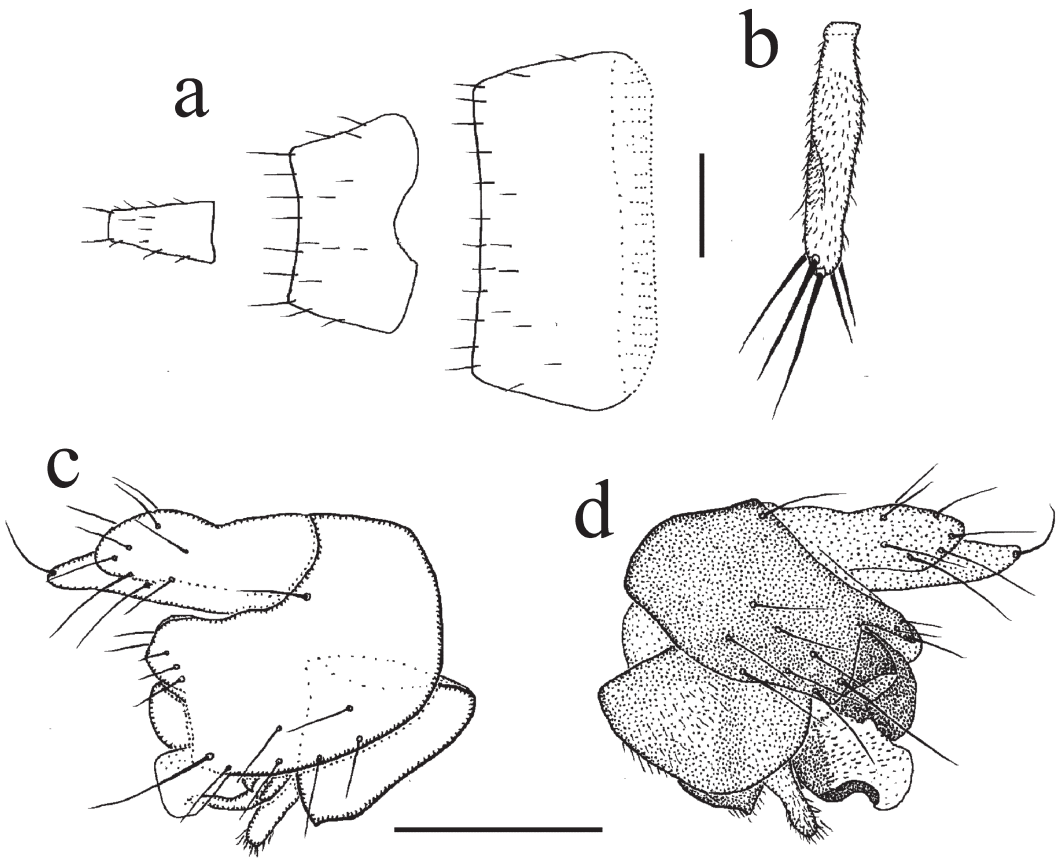

Fig. 1. Megaselia excorticata sp. $\mathrm{n}$. - a. Female, abdominal tergites 5-7. - b. Male, right palp from above. - c. Male, right face of hypopygium. - d. Left face of hypopygium. Scale bars $=0.1 \mathrm{~mm}$.

Schmitz collection (Museum Alexander Koenig, Bonn) was remounted in Euparal.

The tree species sampled were trembling aspen (Populus tremula), silver birch (Betula pendula), Scot's pine (Pinus sylvestris) and Norway spruce (Picea abies).

\section{The species}

The species obtained were all members of the huge genus Megaselia Rondani. The keys to the males of British species (Disney 1989) and the literature cited therein cover most of the European species. However, additions and amendments are constantly being made (e.g. Disney 2003).

The specimens are deposited in the Cambridge University Museum of Zoology (CUMZ). In citing this, two sets of numbers are given, e.g. (298, CUMZ, 13-73). The 298 refers to the sample number the 13-73 refers the author's notebook 13 and its page 73 .

\section{Megaselia excorticata sp. $n$. (Fig. 1a-d)}

This species closely resembles Megaselia ignobilis (Schmitz) (see below), which has been re- ported breeding in a rot hole in an oak tree (Quercus petraea) (Godfrey \& Disney 2002).

Male. Frons brown, clearly broader than long, with 40-42 hairs and dense fine microsetae. Bristle arrangement similar to Fig. 2d, with the lower supra-antennals shorter and weaker than upper pair, but stronger than the longest bristles on palps. Cheek with three bristles and jowl with two. The globose postpedicels brown and without SPS vesicles. Palps pale dusky yellow and as Fig. 1b. Labrum paler than palps and about half as wide as a postpedicel. Labella also pale, relatively narrow, and with only a few short spinules below. Thorax brown. Three notopleural bristles and no cleft in front of these. Mesopleuron with four hairs. Scutellum with an anterior pair of hairs (at most as large as those in middle of scutum) and a posterior pair of bristles. Abdominal tergites brown with hairs mainly in rear thirds and only a little longer at rear of T6. Venter grey, and with a few small hairs on segments 3-6. Hypopygium largely brown, with a pale brown anal tube, and as Fig. 1c-d. Legs with brown coxae to tibiae on the middle and hind legs, with mainly pale brown coxae to femora on front legs and the rest straw yellow. Fore tarsus with posterodorsal hair palisade on segments 1-4 and 4 and 5 subequal in length. The slightly anterodorsal hair palisade of 
Fig 2. Megaselia ignobilis. - a. Male, left face of hypopygium. $-b$. Right face of hypopygium. - c. Male, right palp from above. $-\mathrm{d}$. Female, frons with bristles represented by their basal sockets only. - e. Female, abdominal tergites $5-7$. Scale bars $=0.1 \mathrm{~mm}$.
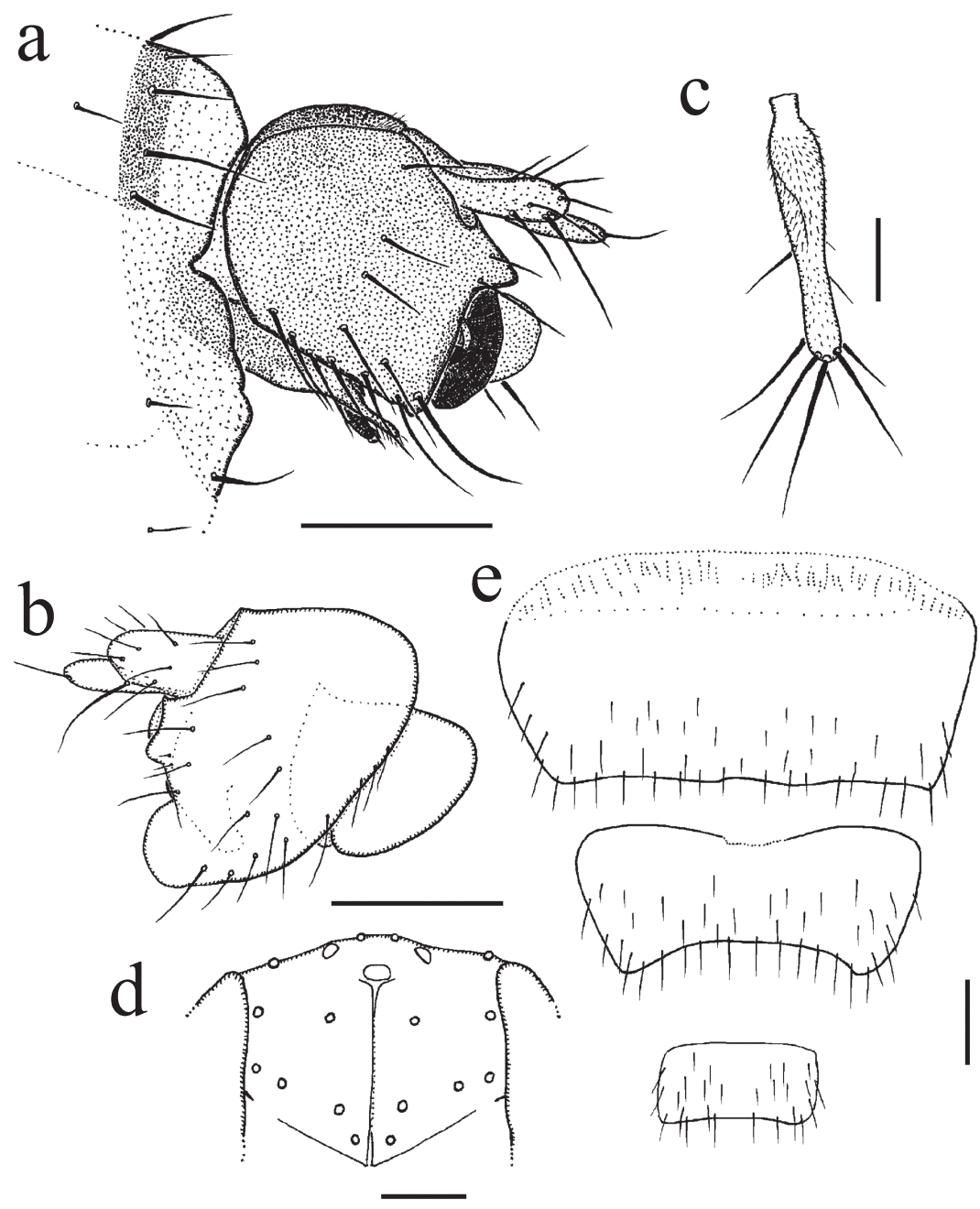

mid tibia extends just over two fifths of its length. Hairs below basal half of hind femur a little shorter than those of anteroventral row of outer half. Hind tibia with 15-16 differentiated posterodorsal hairs and spinules of apical combs simple. Wings $1.2 \mathrm{~mm}$ long. Costal index 0.40. Costal ratios $3.90: 0.92: 1$. Costal cilia (of section 3) $0.07-0.08 \mathrm{~mm}$ long. No hair at base of vein 3 . With two axillary bristles, the outer being a little longer than costal cilia. Sc not reaching R1. All veins grey, but 7 very pale. Membrane only lightly tinged grey. Haltere brown.

Female. Frons similar to male but with up to 50 hairs. Labrum $0.7 \mathrm{x}$ as wide as diameter of postpedicel. Otherwise head similar to male. Thorax as male, but with 2-4 (most with 3) hairs on mesopleuron. Abdominal tergites coloured and haired as male. T5-T7 as Fig. 1. Venter grey and with hairs below segments 3-6 as in male. Sternite 7 absent. Posterolateral lobes at rear of sternum 8 truncated and with 3 longer hairs at rear margin and 4-6 shorter hairs in front of these. Cerci whitish grey and about twice as long as wide. Neither the rectal papillae, the furca, nor Dufour's crop mechanism evident. Legs similar to male. Wing as male except length is $1.2-1.3$ $\mathrm{mm}$. Costal index as little as 0.36 . Costal ratios $3.5-5.6: 0.8-1.8: 1$. Otherwise it and haltere as male.

Material examined. Holotype male, Finland, Sotkamo, Hiidenportti National Park, grid ref. 7090405:3601477, ex aspen log (base), 17.VIII. 2006 (276, CUMZ: 13-75). Paratypes: 1 female as holotype; 1 male, 3 females as holotype except 


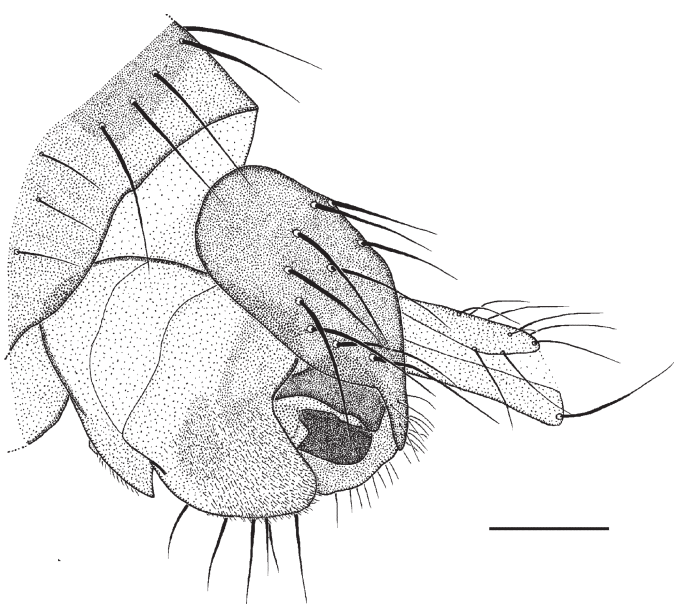

Fig. 3. Megaselia limburgensis male, left face of hypopygium tilted a little dorsally. Scale bar $=0.1 \mathrm{~mm}$.

grid ref. 7088702: 3603800, 31.VII.2004, 7. \& 14.VIII.2006 (298, 298A, CUMZ, 13-73 \& 77); 1 female, Puolanka, Paljakka Strict Nature Reserve, grid ref. 7182240:3550701, ex aspen log (mid), 2.-9.IX.2004 (373, CUMZ: 13-76); 1 female, Puolanka, Paljakka Strict Nature Reserve, grid ref. 7181573:3550145, ex silver birch log (canopy), 29.VI.2005 (385, CUMZ: 13-76).

Etymology. The name refers to the species being reared from the bark of logs.

Affinities. In the keys to the males of the British species (Disney 1989) the male runs to couplet 130, to M. ignobilis (Schmitz), however its hypopygium differs (cf. Figs. 1c-d and $2 \mathrm{a}-\mathrm{b}$ ) and palp is a little smaller (cf. Figs.1b and 2c).

In the keys of Schmitz \& Delage (1974) the male runs to couplet 14 on page 639 , where taking either lead proceeds to species with different hypopygia. If some males possess a costal index and ratios similar to some of the females then it would run out to $M$. divergens (Malloch) at couplet 6 (on page 638). This, however, is a misidentification for M. fenestralis (Schmitz) which was subsequently rescued from synonymy with Malloch's Nearctic species (Disney 1987). M. fenestralis males have thicker fore tarsi (like $M$. divergens), with segment 5 distinctly longer than 4, and a different hypopygium (e.g. with distinctly longer hairs at the tip of the proctiger).

The female closely resembles that of $M$. ignobilis, but differs in the shape of abdominal tergites 5-7 (cf Figs. 1a and 2e) and the narrower

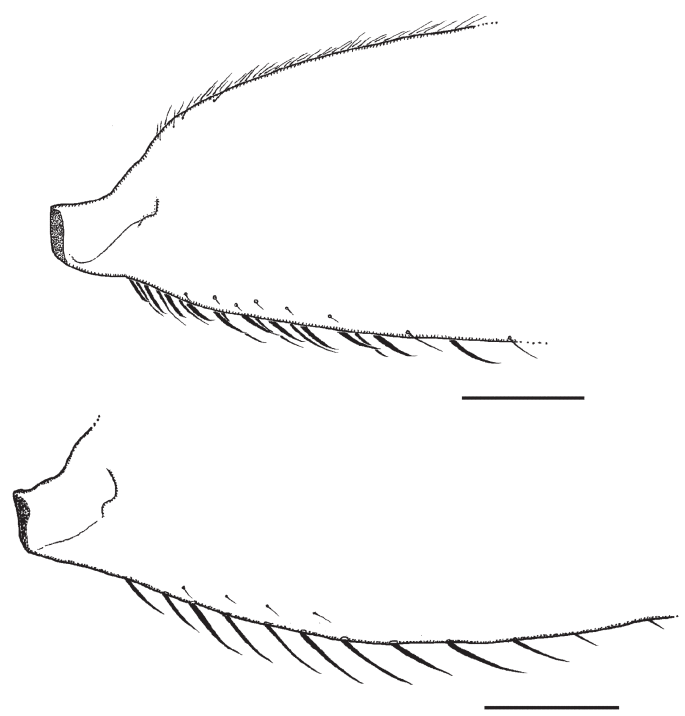

Fig. 4. Megaselia limburgensis male, posterior faces of the bases of the hind femora of two different specimens. Scale bars $=0.1 \mathrm{~mm}$.

labella. The female of $M$. fenestralis has longer darker cerci and a brown labrum.

\section{Megaselia limburgensis (Schmitz, 1918) (Figs 3, 4)}

Aphiochaeta limburgensis Schmitz, 1918: 57.

This species was described without any figures of critical features and its recognition has since caused problems. Thus Robinson (1981) mistakenly synonymised it with $M$. fungivora (Wood) on the basis of the Nearctic specimens attributed to M. limburgensis by Borgmeier (1964). However, Borgmeier had misidentified his specimens. The specimen from Finland is somewhat larger, with a wing length of $2.1 \mathrm{~mm}$, than as indicated by Schmitz (1957), who gave the wing length as $1.75 \mathrm{~mm}$. However, the hypopygium (Fig. 3) matches that of smaller specimens.

Material examined. Finland: 1 male, Kuhmo, Juortanansalo-Lapinsuo Mire Reserve, grid ref. 7166566:637974, ex spruce log (canopy), 20 VI 2006 (237, CUMZ: 13-74).

Natural history. This species has been reported from the leaf mine of the agromyzid Phytomyza soenderupi on Caltha palustris (Ranunculaceae) (Hering 1951) and Schmitz 

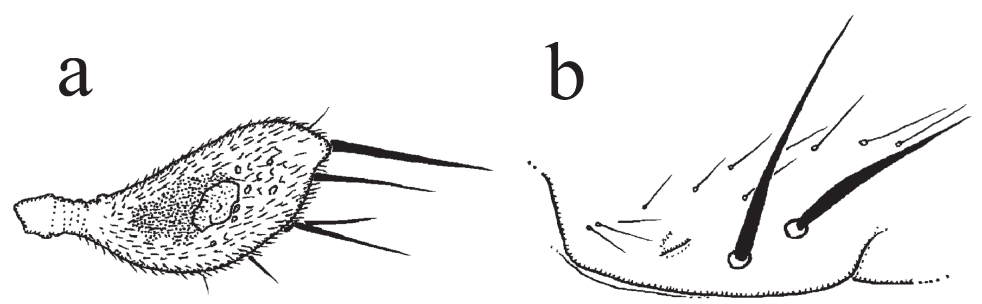

Fig. 5. Megaselia miki male. - a. Right palp. - b. Left notopleuron. -c. Right face of epandrium and hypandrium. - d. Left face of hypopygium. Scale bar $=0.1$ $\mathrm{mm}$.
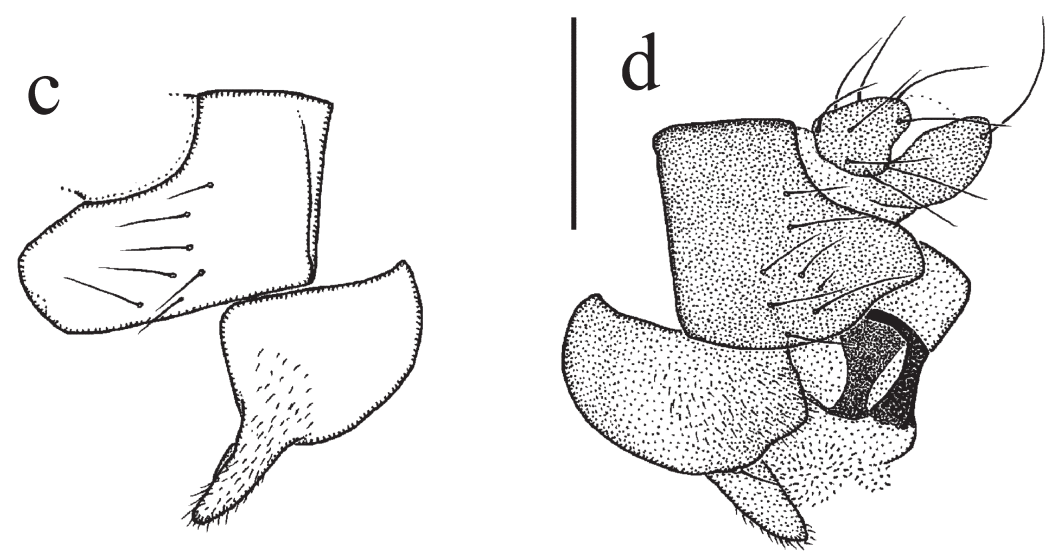

(1957) reported it reared from the frass of curculionid and scolytid beetles.

\section{Megaselia longifurca (Lundbeck, 1921)}

Aphiochaeta lingifurca Lundbeck, 1921: 141.

The recognition of this species was clarified by Disney (1999).

Material examined. Finland: 1 male, Kuhmo, Ulvinsalo Strict Nature Reserve, grid ref. 7098950:36629493, ex aspen log (base), 20.-26. VII.2005 (3); 1 female, same locality, grid ref. 7099418 3663224, ex spruce log (mid), 13-19. VII.2005 (45). 1 male, Kuhmo, Elimyssalo Nature Reserve, grid ref. 7126522:3660575, ex spruce log (base), 3.-9.VIII.2005 (105); 1 female, same locality, grid ref. 71265723660480 , ex spruce log (base), 13.-19.VII.2005 (106); 1 female, same locality, grid ref. 7125195:3661592, ex pine log (base), 13.-19.VII.2005 (145). 2 males, Sotkamo, Hiidenportti National Park, grid ref. 7090832:3601382263, ex pine log (base), 3 VII 2006 (263). 1 male, Russia: State Forestry of Kostomuksha (Kostamus) District, grid ref. 7168990:3657471, ex silver birch log (upper), 10.VII.2006 (467).
Natural history. The larvae prey upon the eggs of spiders (probably Enoplognatha or Robertus, Theridiidae), Argiope sp. (Araneidae), plus egg sacs of unknown spiders, there being 120 (mean 5.0) adult flies reared per sac. Recorded infestation rates were $11.6-20.0 \%$. A rearing from an unidentified agaric sporophore possibly originated from an overlooked spider egg sac concealed between the gills of the fungus (Disney 1994, 1999). Adults represented up to $4.7 \%$ of the Phoridae obtained from the canopies of oak trees (Quercus spp.) in woods near Oxford (1980 1984), using the insecticide knockdown method (Disney 1994, 1999).

\section{Megaselia miki Schmitz, 1929 (Fig. 5a-d)}

Megaselia miki Schmitz, 1929: 127.

This species was described from males only and without any figures, but I have previously examined two paratypes in the Museum Koenig (Bonn) which allows me to confirm the identification. The male readily runs to couplet 270 in the key to the males of the British species of Megaselia (Disney 1989) and then runs into diffi- 
culties beyond this point. However, it has a distinctive hypopygium (Fig. 5c, d), a fine notopleural cleft in front of the two bristles on the notopleuron (Fig. 5b), a conspicuous sensory pit on the palp (Fig. 5a) and at least two dozen subcutaneous pit sensilla in the postpedicel.

Material examined. Finland, 1 male, Kuhmo, Juortanansalo-Lapinsuo Mire Reserve, grid ref. 7167884 3642689, ex pine log (base), 20.26.VII.2005 (186, CUMZ: 13-73).

\section{Megaselia robertsoni Disney, 2008}

Megaselia robertsoni Disney, 2008: 65.

This species was described from a single male reared from a pupa found under the bark of a spruce stump in Norway.

Material examined. 1 male, Finland, Sotkamo, Hiidenportti National Park, grid ref. 7088702 3603800, ex aspen log (base), 31.VII.2004 (298A, CUMZ: 13-77).

\section{Megaselia setulipalpis Schmitz, 1938 (Figs. 6a-b, 7a-d)}

Megaselia setulipalpis Schmitz, 1938: 187.

I have remounted the holotype male of $M$. setulipalpis in Euparal. Schmitz (1958, Textfig. 242) illustrated the terminal abdominal segments of the female.

Schmitz (1958) gave the wing length of the male as $1.7 \mathrm{~mm}$, the costal index as $0.48-0.50$, the costal ratios as $2.9-3.7: 1.5-1.9: 1$ and the length of the costal cilia as $0.08-0.09 \mathrm{~mm}$. For males from Britain, the wing lengths range from 1.3-1.8 $\mathrm{mm}$, the costal index ranges from $0.47-0.50$ and the ratios and costal cilia lengths cover the same ranges, but a specimen from Poland has the costal ratios as $4.5: 2.5: 1$ and the costal cilia as 0.10 $\mathrm{mm}$ long. For the female Schmitz gave the CI as 0.50 and the costal ratios as $3.1: 1.5-1.6: 1$. For the two females below the ranges are 1.9-2.1 mm for the wing length, $0.49-0.50$ for the costal index, 3.4-3.7 : 1.6-1.9: 1 for the costal ratios, and 0.09-0.10 for the length of the costal cilia.

Material examined: 1 female, Finland, Kuhmo, Elimyssalo Nature Reserve, grid ref.

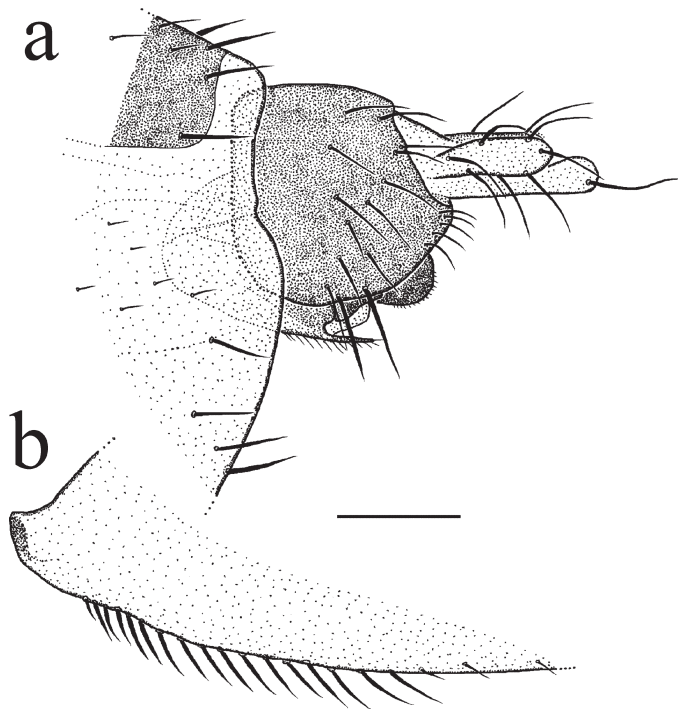

Fig. 6. Megaselia setulipalpis male. - a. Left face of hypopygium (tiled a little towards viewer). - b). Posterior face of base of hind femur. Scale bar $=0.1 \mathrm{~mm}$.

7126008:3660548, spruce (branch), 3.VII.2006 (124); 1 female, Kuhmo, Juortanansalo-Lapinsuo Mire Reserve, grid ref. 7167560: 3643110193, ex silver birch (branch), 26.VI-5.VII.2005 (193).

Other material examined: Holotype male, The Netherlands, Valkenburg, 20.VII-10.VIII. 1933, H. Schmitz (ZFMK). 2 males, England, North Yorkshire, Park End Wood, birch wood (Grid ref. 35/923260), 22.-25.VI.1981, R. H. L. Disney (CUMZ, 7-100). 1 male, Germany, Ulm, 13.-21.V.1992, M. Buck(VH1 TE3, CUMZ, 260). 1 male, Poland, Forest of Bialowieska, 27.VIII.1987, E. Durska (667Bf, CUMZ, 8-74). 2 males, 1 female, Scotland, Aviemore, by River Spey (Grid ref. 28/893112), alder carr, 9.-13.VII. 1982, R. H. L. Disney (CUMZ, 8-29); 1 male, Craigellachie National Nature Reserve (Grid ref. 28/891116), 13.VII.1982, R. H. L. Disney (CUMZ, 8-41).

Natural history. Adults have previously been reported emerging in numbers from the trunk of a dead spruce (Prescher\& Wermelinger, unpublished; cited by Weber et al. 2007). However, Dr Sabine Prescher kindly confirmed that this species was that described below and sent me a male and female from this series (see below) 


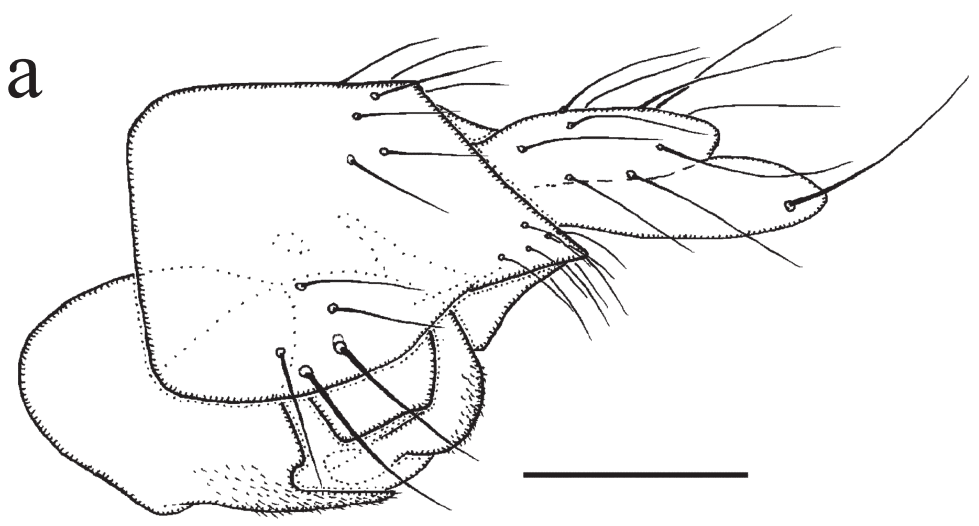

Fig. 7. Megaselia setulipalpis. - a. Male, left face of hypopygium. - b. Female, right labellum and glossa from below. - c. Male, frons with bristles represented by their basal sockets only (al = anterolatral, $\mathrm{a}=$ antial, usa = upper supraantennal). - d. Female, abdominal tergites $5-7$. Scale bars $=0.1 \mathrm{~mm}$. $\mathrm{b}$

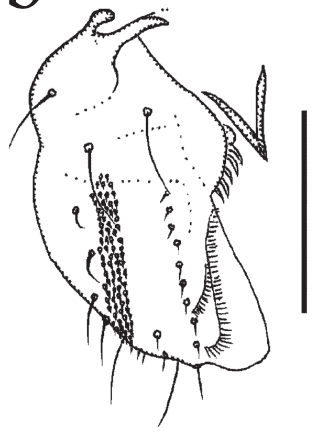

d
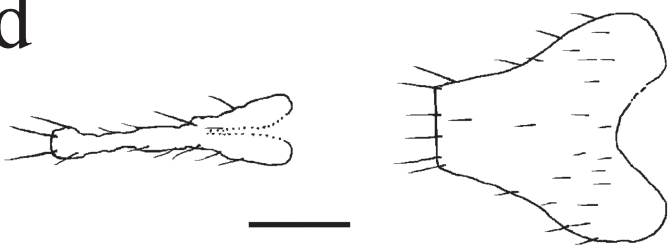

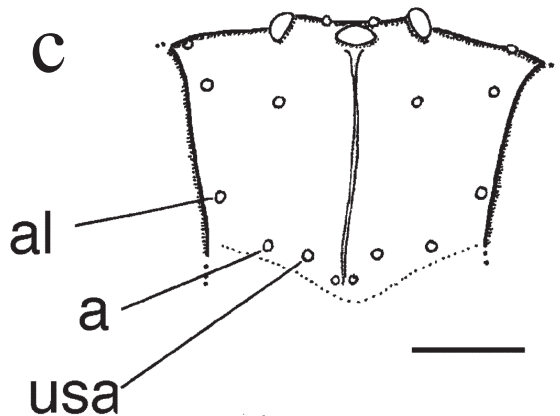

\section{Megaselia tignorum sp. $\mathrm{n}$.} (Fig. 8a-d)

This species closely resembles $M$. setulipalpis (see below).

Male. Frons brown, clearly broader than long, with 52-62 hairs and dense but very fine microsetae. Bristles arrangement on frons similar to Fig. 7c, but the upper SAs tend to be a little higher on the frons than the antials and the latter tend to be a little closer to the ALs than to the SAs. Cheek with 2-4 bristles and jowl with 2-4 longer ones. Postpedicels brown, subglobose and without SPS vesicles. Palps dusky straw yellow, about
$0.4 \mathrm{x}$ as broad as postpedicel but longer than breadth of latter, with three longer and three shorter bristles and 3-7 hairs. Labrum pale straw yellow and at most $0.6 \mathrm{x}$ as wide as postpedicel. Labella pale yellow, but partly pale brown on top, and with numerous short spinules below not obviously arranged in rows. Thorax brown. Three notopleural bristles and no cleft in front of these. Mesopleuron with 8-17 hairs and 1-2 differentiated bristles at rear margin. Scutellum with an anterior pair of hairs (shorter than those in middle of scutum) and a posterior pair of bristles. Abdominal tergites brown with hairs at rear margins longer than rest and those at rear of T6 the longest. 


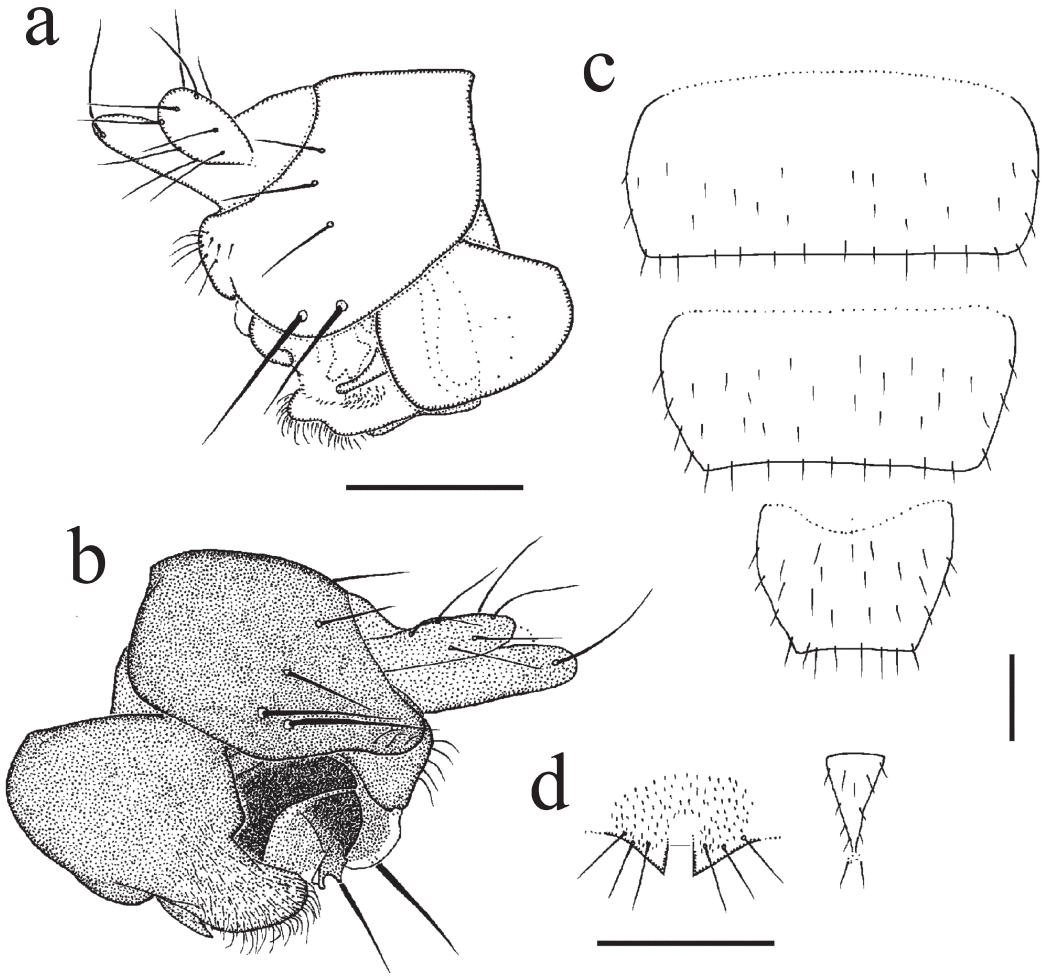

Fig. 8. Megaselia tignorum. - a. Male, right face of hypopygium. - b. Left face of hypopygium. $-\mathrm{c}$. Female, abdominal tergites 4-7. - d. Female, lobes at rear of abdominal sternum 8 . Scale bars $=0.1 \mathrm{~mm}$.
Venter brown, and with hairs on segments 3-6. Hypopygium brown, with a pale brown anal tube and straw yellow left lobe of the hypandrium, and as Fig. 8a and 8b. Mid and hind legs with brown coxae to tibiae and dirty yellow tarsi. Front legs with coxae and femora part brown and part straw yellow and rest dusky yellow. Fore tarsus with posterodorsal hair palisade on segments $1-5$ and 5 about as long as 4. Dorsal hair palisade of mid tibia extends two fifths to half its length. Hairs below basal half of hind femur about as long as those of anteroventral row of outer half. Hind tibia with a dozen or more differentiated posterodorsal hairs and spinules of apical combs simple. Wings $1.3-1.6 \mathrm{~mm}$ long. Costal index 0.45-0.47. Costal ratios 3.4-4.6:1.5-1.8: 1. Costal cilia (of section 3) 0.07-0.09 mm long. A small hair at base of vein 3 present or absent, when present it is as small as the first hairs at base of costa. With 3 axillary bristles, the outer two being longer than costal cilia. Sc not reaching R1. All veins light grey. Membrane lightly tinged grey (just evident to naked eye when viewed against a white background). Haltere brown.

Female. Head similar to male but the labrum about $0.7 \mathrm{x}$ as wide the diameter of postpedicel. Thorax as male, there being 9-11 hairs plus the bristle on the mesopleuron. Abdominal tergites brown. T4-T7 as Fig. 8c. Venter brownish grey, and with hairs below segments 3-6. Sternite 7 represented by hairs only. Posterolateral lobes at rear of sternum 8 as Fig. 8d. Cerci pale but lightly tinged brown and about twice as long as broad. With four rectal papillae. Furca not evident. Dufour's crop mechanism bilobed behind. Legs similar to male but hairs below basal half of hind femur are shorter than those of anteroventral row in distal half. Wing as male, with wing length 1.3 $1.4 \mathrm{~mm}$, costal index $0.45-0.46$, costal ratios 3.6$3.9: 1.6-1.8: 1$ and costal cilia $0.07-0.08 \mathrm{~mm}$ long. Otherwise it and haltere as male.

Material examined. Holotype male, Finland, Kuhmo, Ulvinsalo Strict Nature Reserve, grid ref. 7099758:3662603, ex spruce log (mid), 2228.VI.2005 (19); 1 male, Kuhmo, JuortanansaloLapinsuo Mire Reserve, grid ref. 7168158: 3642387, spruce log (base), 20.-26.VII.2005 (180); 1 male, same locality, grid ref. 7166566: 3637974, ex spruce log (mid), 3.-9.VIII.2005 (237); 1 male, Puolanka, Paljakka Strict Nature 
Reserve, grid ref. 7183767 3550404, pine log (mid), 20.-26.VII.2005, (358); 1 female, Finland, Puolanka, Paljakka Strict Nature Reserve, grid ref. 7180449:3550938, ex spruce log (base), 2024.VII.2005 (390, CUMZ, 13-72); 1 male, same locality, spruce log (mid), 12.VII.-2.VIII.2005 (362). 1 male, England, North Yorkshire, Malham Tarn National Nature Reserve, North edge of East Fen (Grid ref. 34/889672), pitfall trap, 28.29.VI.1984 (CUMZ, 14-18). 1 male, 1 female, Switzerland, Sernftal, ex spruce trunk, 17.V. \& 30.VIII.1995, B. Wermelinger (leg. Dr Sabine Prescher) (CUMZ, 13-77).

Etymology. The name refers to procurement from logs.

Affinities. In the keys to the males of the British species (Disney 1989) the male runs to couplet 59, where it runs to $M$. setulipalpis but the hairs below the basal half of the hind femur are fewer and not so robust. A note suggests that if neither lead applies one should try couplet 92 , from where one then proceeds to couplet 98, where clearly neither lead applies. In the keys of Schmitz (1957) the male runs to couplet 21, on page 432, to M. setulipalpis.

Both the male and female are distinguished from $M$. setulipalpis by having the spinules on the lower face of the labella being not restricted to a narrow band on each. Those of the male of $M$. setulipalpis are in 6-7 irregular rows but there are fewer rows in the female (Fig. 7b). In the new species they are not crowded into such rows but are more generally dispersed. The posterolateral margins of the right side of the epandrium differ, with that of $M$. setulipalpis sloping forwards, as opposed to being directed more ventrally (cf Fig. $7 \mathrm{a}$ with Fig. $8 \mathrm{a}$ and $8 \mathrm{~b}$ ). The females are further distinguished by their abdominal tergites 6 (cf Figs. 7d and 8c). In this its T6 resembles that of M. armata (Wood). However, the paired lobes at the rear of abdominal sternum 8 of Wood's species lack the pale bare points of the new species (Fig. 8d). In both sexes the costal index is a little less than in M. setulipalpis.

Natural history. The two paratypes from Switzerland were from the series previously reported emerging in numbers from the trunk of a dead spruce (cited by Weber et al. 2007), the species being referred to as $M$. setulipalpis.

\section{Megaselia species not determined $A$}

This species resembles the female of $M$. tignorum, but it is larger (wing length about 1.9, as opposed to $<1.5 \mathrm{~mm}$ ), with a longer costal index ( 0.50 as opposed to $0.45-0.46$ ) and longer costal cilia $(0.11-0.12$ as opposed to $0.08 \mathrm{~mm})$. It is possibly the hitherto unknown female of $M$. insons (Lundbeck) (see below).

Female. Frons brown, clearly broader than long, with 52-54 hairs and dense but very fine microsetae. SAs unequal, the lower pair being shorter and weaker. The antials very slightly lower on frons than upper SAs but the anterolaterals slightly higher, and closer to latter than to upper SAs. Pre-ocellars a little closer together than either is from a mediolateral bristle, and all four bristles in an almost straight line. Cheek with four bristles and jowl with two longer ones. The subglobose postpedicels dark brown, without SPS vesicles. Palps straw yellow, with five strong bristles, one weaker one and half a dozen hairs. Labrum coloured as palps and about three quarters the width of a postpedicel. Labella paler and with up to 50 short spinules below each. Thorax brown. Three notopleural bristles and no cleft in front of these. Mesopleuron with 8 small hairs and on one side only with a short differentiated bristle as well. Scutellum with an anterior pair of hairs (about equal to those in middle of scutum) and a posterior pair of bristles. Abdominal tergites brown, with the hairs at rear of T6 and T7 distinctly longer than the rest. T8 is clearly longer than in M. setulipalpis and M. tignorum, being about $0.15 \mathrm{~mm}$ long and thus almost as long as $\mathrm{T} 7$ (which is about $0.16 \mathrm{~mm}$ long). Venter brown, and with hairs below segments 3-6. Sternite 7 about $0.10 \mathrm{~mm}$ long. Posterolateral lobes at rear of sternum 8 very short but with 3-4 strong hairs at rear margin. Cerci light brown and about $2.2 \mathrm{x}$ as long as broad. With four rectal papillae. Dufour's crop mechanism about 0.34 $\mathrm{mm}$ long and bilobed behind. Legs with brown mid and hind femora, part straw yellow part brown mid and hind tibiae, and the rest mainly a dusky straw yellow apart from brown patch on mid coxa. Fore tarsus with posterodorsal hair palisade on segments $1-5$ and 5 not longer than 4 . Dorsal hair palisade of mid tibia extends about 
two thirds of its length. Hairs below basal half of hind femur, being about as strong as those on the anterior face, are clearly shorter than those of anteroventral row of outer half. Hind tibia with 17-18 differentiated posterodorsal hairs and spinules of apical combs simple. Wings $1.6-1.9 \mathrm{~mm}$ long. Costal index 0.49-0.50. Costal ratios 3.2$3.5: 1.7-1.8: 1$. Costal cilia (of section 3 ) $0.11-$ $0.12 \mathrm{~mm}$ long. Hair at base of vein 3 very small, being shorter than width of vein. With four axillary bristles, all being shorter than longest costal cilia. Sc not reaching R1. Thick veins greyish yellow, thin veins grey. Membrane lightly tinged grey (just evident to naked eye when viewed against a white background). Haltere brown.

Material examined. 1 female, Finland: Sotkamo, Hiidenportti National Park, grid ref. 7088702:3603800, ex aspen log, 31.VII.2004 (298A, CUMZ: 13-77); 1 female, Puolanka, Paljakka Strict Nature Reserve, grid ref. 7182440:3550688, ex aspen log (base), 14.VIII. 2006 (377, CUMZ, 13-76).

Affinities. In the keys of Schmitz (1957), if this species is regarded as having a differentiated bristle at the rear margin of the mesopleuron, it will run to couplet 17 on page 432 . If the costal cilia are treated as short it will run on to $M$. setulipalpis, from which the scattered spinules of the ventral faces of the labella will immediately distinguish it. The longer costal index will distinguish it from $M$. tignorum (above). If at couplet 17 one takes the second lead one proceeds to couplet 30 . Of the five species covered by the remaining three couplets three have been synonymised with $M$. frameata Schmitz, leaving only it and $M$. insons (Lundbeck), whose female is unknown. However, two further species of this complex have been described since (Disney 2006, 2008). The bilobed dufour's crop mechanism immediately distinguishes it from $M$. frameata and $M$. shawi. The female of M. robertsoni (2008) is unknown, but its male is smaller (wing length 1.3 $\mathrm{mm})$, its costal index shorter (0.46) and likewise its costal cilia $(0.07 \mathrm{~mm})$.

If this species is regarded as having hairs only on the mesopleuron, and with the costal cilia $<0.10 \mathrm{~mm}$ long (or at most $<0.125 \mathrm{~mm}$ ), in the keys of Schmitz (1958) to Abteilung IV, Erste Reihe it will run, with some difficulty and refer- ence to the text to circumvent couplets based on the male sex only, to couplet 18 , to M. setulipalpis (from which it is distinguished in the previous paragraph). However, the costal cilia on section 1 are longer and so this species could equally be taken through the keys of Schmitz \& Beyer (1965) to Abteilung IV, Zweite Reihe. However, this key relies heavily on male features and, even with frequent reference to the text for information on females, is not easy to use with confidence. It seems most readily to run out to couplets 83 to 97 but cannot be assigned with confidence to any species in this section.

It is most probable that this specimen is the hitherto unknown female of $M$. insons, but until associated with the male this remains only a tentative hypothesis requiring testing.

\section{Megaselia species not determined $B$}

The single male is probably an undescribed species, however the specimen is somewhat teneral and is not being fully described until a better specimen is available. In the keys to British species (Disney1989) it runs to couplet 126, but the hypopygium will distinguish it from the two species of this couplet. Of the non-British European species that run to the same couplet $M$. aristica (Schmitz) and $M$. digitalis Schmitz not only have different hypopygia but their anterolateral bristles on the frons are almost level with the antials, but in species B the ALs are clearly higher on the frons. The species M. jameslamonti Disney has a much longer anal tube than species B. The key details of the wing are wing length $1.0 \mathrm{~mm}$; costal index $0.36-0.37$; costal ratios $3.9: 1.1: 1$; costal cilia $0.06 \mathrm{~mm}$ long; and the haltere is brown. These features allow it to run to couplet 13 on page 639 of the key of Schmitz \& Delage (1974). However, this couplet refers to the females only of two species whose males run to couplet 9, and which are distinguished by their distinctive hypopygia.

Material examined: 1 male, Russia: State Forestry of Kostomuksha (Kostamus) District, grid ref. 7169259:3657699, ex silver birch log, 6.IX. 2005 (470A, CUMZ, 13-78). 
Acknowledgements. I am grateful to Dr Netta Dorchin (Museum Koenig, Bonn) for the loan of the holotype of $M$. setulipalpis and to Dr Sabine Prescher (Braunsweig) for the gift of a male and female of the series previously reported from a dead spruce. My studies of Phoridae are currently supported by a grant from the Balfour-Browne Trust Fund (University of Cambridge). I am grateful to Dr Gergely Várkonyi, Friendship Park Research Centre, for arranging payment of the page charges and to his staff who carried out the field work and sorted the specimens to family.

\section{References}

Borgmeier, T. 1964: Revision of the North American Phorid flies.Part II. The species of the genus Megaselia, subgenus Aphiochaeta (Diptera, Phoridae). — Studia Entomologica, Petropolis 7: 257-416.

Büchs, W. 1983: Jahresperiodische Aktivität und Weschselbeziehungen von Arthropoden aus der Stammregion eines Hartholzauenwaldes (Fraxino-Ulmetum). - Verhandlungen der deutschen Zoologischen Gesellschaft 1983: 210.

Büchs, W. 1988: Stamm- und Rinden-zoozönosen verschiedener Baumarten des Hartholzauenwaldes und uhr Indikatorwert für die Früherkennung von Baumschäden. Bonn: Rheinische Friederich — Ph.D. Thesis, Wilhelms-Universität.

Disney, R. H. L. 1979: Natural history notes on some British Phoridae (Diptera) with comments on a changing picture. - Entomologist's Gazette 30: 141-150

Disney, R. H. L. 1980: A scuttle fly (Dipt., Phoridae) that parasitises larvae of Trichosia Winnertz (Dipt., Sciaridae). - Entomologist's Monthly Magazine 116: 5-6.

Disney, R. H. L. 1987: Rescue of Megaselia fenestralis (Diptera: Phoridae) from synonymy and its removal from British List. — Entomologist's Gazette 38: 13.

Disney, R. H. L. 1989: Scuttle Flies - Diptera Phoridae Genus Megaselia. - Handbooks for the Identification of British Insects 10: 1-155.

Disney, R. H. L. 1994: Scuttle Flies: The Phoridae. Chapman \& Hall, London.

Disney, R. H. L. 1999: A troublesome sibling species complex of scuttle Flies (Diptera: Phoridae) revisited. Journal of Natural History 33: 1159-1216.

Disney, R. H. L. 2001: The preservation of small Diptera. — Entomologist's Monthly Magazine 137: 155-159.

Disney, R. H. L. 2003: Revisionary notes on European (Diptera). - Bonner zoologische Beiträge 50: 293304.
Disney, R. H. L. 2006: Anew species of Megaselia Rondani (Dipt., Phoridae) from Britain and a new synonym. — Entomologist's Monthly Magazine 142: 31-39.

Disney, R. H. L. 2008: A new species of the Megaselia fungivora (Wood) species complex (Dipt., Phoridae) from Norway. - Entomologist's Monthly Magazine 144: 65-67.

Godfrey, A. \& Disney, R. H. L. 2002: Scuttle Flies (Diptera, Phoridae) from a large rothole in an oak tree in England. - Dipterists Digest 9: 165-171.

Hering, E. M. 1951: Biology of the Leaf Miners. - Gravenhage: Junk.

Lundbeck, W. 1921: New species of Phoridae from Denmark, together with remarks on Aphiochaeta groenlandica Lundb. - Videnskabelige Meddelelser fra Dansk naturhistorisk Forening i Kjøbenhavn 72: 129_ 143.

McLean, I. F. G. 2000: Beneficial Diptera and their role in decomposition. - In: Papp, L. \& Darvas, B. (eds.), Contributions to a Manual of Palaearctic Diptera. Volume 1. General and Applied Dipterology. Budapest: 491-517. Science Herald.

Robinson, W. H. 1981: Terminalia of North American species of Group II Megaselia (Aphiochaeta) and descriptions of four new species (Diptera: Phoridae). — Proceedings of the Entomological Society of Washington 83: 489-504.

Schmitz, H. 1918: Neue europäische Aphiochaeta-Arten I (Dipt.). - Entomologische Berichten de Nederlandsche Entomologische Vereeniging 5: 57-62.

Schmitz, H. 1929: Neue Megaselia-Arten. II. — Natuurhistorisch Maandblad 18: 124-127.

Schmitz, H. 1938. On the Irish species of the Dipterous family Phoridae. - Proceedings of the Royal Irish Academy 44B: 73-204.

Schmitz, H. 1957: Phoridae. — In: Lindner, E. (ed.), Die Fliegen der palaearktischen Region 4(33) (Lieferung 196): 417-464.

Schmitz, H. 1958: Phoridae. — In: Lindner, E. (ed.), Die Fliegen der palaearktischen Region 4(33) (Lieferung 202): 465-512.

Schmitz, H. \& Beyer, E. 1965: Phoridae. - In: Lindner, E. (ed.), Die Fliegen der palaearktischen Region 4(33) (Lieferung 258, 260): 513-608.

Schmitz, H. \& Delage, A. 1974: Phoridae. — In: Lindner, E. (ed.), Die Fliegen der palaearktischen Region 4(33) (Lieferung 301): 638-64.

Weber, G., Prescher, S., Ulefors, S-O., Viklund, B. 2007 (2006): Fifty-eight species of scuttle flies (Diptera, Phoridae): Megaselia spp.) new to Sweden from the Tyrestra National Park and Nature Reserve. - Studia dipterologica 13: 231-240. 